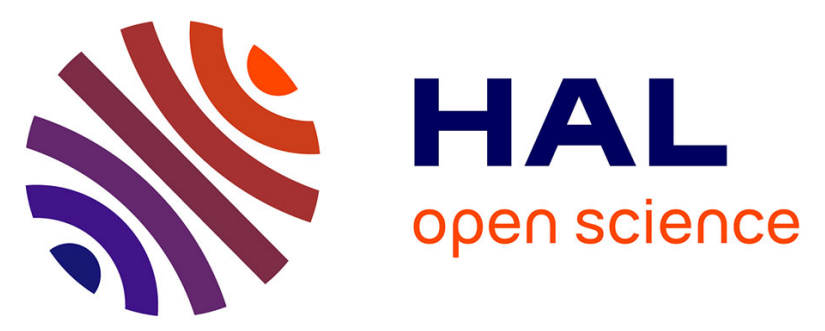

\title{
Sintering Temperature Effects on Structural, Magnetic, Magnetocaloric and Critical Properties of Nd0.67Pb0.33Mn0.9Al0.1O3 Manganites
}

\author{
Abdelbaki Guedri, Sobhi Hcini, Bandar Alzahrani, Michel Boudard, \\ Abdessalem Dhahri, Mohamed Lamjed Bouazizi
}

\section{To cite this version:}

Abdelbaki Guedri, Sobhi Hcini, Bandar Alzahrani, Michel Boudard, Abdessalem Dhahri, et al.. Sintering Temperature Effects on Structural, Magnetic, Magnetocaloric and Critical Properties of Nd0.67Pb0.33Mn0.9Al0.1O3 Manganites. Journal of Superconductivity and Novel Magnetism, 2020, 33 (4), pp.1223-1230. 10.1007/s10948-019-05332-0 . hal-03127793

HAL Id: hal-03127793

https://hal.univ-grenoble-alpes.fr/hal-03127793

Submitted on 11 Oct 2021

HAL is a multi-disciplinary open access archive for the deposit and dissemination of scientific research documents, whether they are published or not. The documents may come from teaching and research institutions in France or abroad, or from public or private research centers.
L'archive ouverte pluridisciplinaire HAL, est destinée au dépôt et à la diffusion de documents scientifiques de niveau recherche, publiés ou non, émanant des établissements d'enseignement et de recherche français ou étrangers, des laboratoires publics ou privés. 


\title{
Sintering-temperature effects on structural, magnetic, magnetocaloric and critical properties of $\mathrm{Nd}_{0.67} \mathrm{~Pb}_{0.33} \mathrm{Mn}_{0.9} \mathrm{Al}_{0.1} \mathrm{O}_{3}$ manganites
}

\author{
Abdelbaki Guedri ${ }^{1,2}$, Sobhi Hcini ${ }^{1,}$, Bandar Alzahrani ${ }^{3}$, Michel Boudard ${ }^{4}$, Abdessalem Dhahri ${ }^{2}$, \\ Mohamed Lamjed Bouazizi ${ }^{3}$ \\ ${ }^{1}$ University of Kairouan, Faculty of Science and Technology of Sidi Bouzid, Research unit of \\ valorization and optimization of exploitation of resources, 9100 Sidi Bouzid, Tunisia. \\ ${ }^{2}$ Monastir University, Sciences Faculty, Laboratory of Physical Chemistry of Materials, Physics \\ Department, Tunisia. \\ ${ }^{3}$ Department of Mechanical Engineering, College of Engineering, Prince Sattam Bin Abdulaziz. \\ University, 11942 Alkharj, Saudi Arabia. \\ ${ }^{4}$ University of Grenoble Alpes, LMGP, CNRS, 38000 Grenoble, France. \\ * Corresponding author: E-mail address: hcini_sobhi@yahoo.fr (S. Hcini)
}

\begin{abstract}
We have reported the results of structural, magnetic, and magnetocaloric characterizations as well as the critical behaviors of the polycrystalline $\mathrm{Nd}_{0.67} \mathrm{~Pb}_{0.33} \mathrm{Mn}_{0.9} \mathrm{Al}_{0.1} \mathrm{O}_{3}$ manganites. These samples, denoted as $\mathrm{S} 900$ and $\mathrm{S} 1100$, were prepared using the sol-gel method and sintered separately at $900{ }^{\circ} \mathrm{C}$ and $1100^{\circ} \mathrm{C}$, respectively. XRD analysis shows good crystallization for the samples in the $R \overline{3} c$ rhombohedral structure. From $M(T)$ curves, second order ferromagnetic-paramagnetic (FMPM) phase transitions appear at the Curie temperatures $\left(T_{C}\right)$ around $130 \mathrm{~K}$ and $155 \mathrm{~K}$ for $\mathrm{S} 900$ and S1100, respectively. The estimated values of magnetic entropy change $\left(-\Delta S_{m}\right)$ at $\mu_{0} H=5 \mathrm{~T}$ were found to be 3.23 and $4.41 \mathrm{~J} / \mathrm{kg} . \mathrm{K}$ for S900 and S1100, respectively. The corresponding values of relative cooling power (RCP) are equal to 242 and $245 \mathrm{~J} / \mathrm{kg}$. These values are relatively higher, making our samples promising candidates for magnetic refrigeration technology. We found that the critical exponents $(\beta, \gamma$ and $\delta)$ agree well with those of the mean-field and the 3D-Heisenberg models for S900 and S1100, respectively.
\end{abstract}

Keywords: Manganites; Structural analysis; Magnetic properties; Magnetocaloric properties; Critical behavior. 


\section{Introduction}

The environmental issue occupies a central place in international debates. Global warming in its scale and complexity raises several questions about the future of our planet. One of the means proposed to slow down this process is the reduction of the production of greenhouse gases, which means changing our lifestyle and the advent of more environmentally friendly technologies. As demand grows stronger, the refrigeration and air conditioning industries are trying to renew themselves to meet new environmental standards. Indeed, the operation of current refrigerators has not changed significantly since the early twentieth century and is based on the well-known principle of compression and repeated expansion of gas circulating around an isolated compartment. Since the Montreal Protocol, CFC (chlorofluorocarbon) gases, partly responsible for the destruction of the ozone layer, have been replaced by HCFCs (hydrochlorofluorocarbons) and HFCs (hydrofluorocarbons). However, they contribute to the greenhouse effect. Traditional production of cold has reached its limits; and today, the need to find new, less polluting refrigeration systems is becoming crucial. Research in this field is therefore exploring new ways to remove these harmful gases from our environment. One of the most promising alternatives is so-called "magnetic" refrigeration based on the magnetocaloric effect (MCE) [1].

It is only recently, thanks to advances in materials science and system design, that the magnetocaloric effect is envisaged for applications at room temperature. Gadolinium is the only element to have a strong magnetocaloric effect near room temperature. However, its high price and its poor resistance to aqueous corrosion do not make it possible to compete with conventional refrigeration systems. As a result, current research has focused mainly on two major families: gadolinium-based compounds such as $\mathrm{Gd}_{5}\left(\mathrm{SixGe}_{1-\mathrm{x}}\right)_{4}$ and manganese-based compounds such as $\mathrm{MnFeP}_{1-\mathrm{x}} \mathrm{As}_{\mathrm{x}}$ [2]. It is within this framework that studies on other materials with giant MCE have multiplied, being the subject of numerous studies, both 
fundamental [3-5] and applied [6-9]. The manganites materials represent one of the studied families due to their remarkable MCE [10-16]. The main advantage of this series of compounds is that their $T_{C}$ can be easily tuned to the room temperature by doping $[\mathbf{1 7}, \mathbf{1 8}]$. For example, a large magnetic entropy change was found near room temperature for some manganite systems $[\mathbf{1 8}, \mathbf{1 9}]$.

The subject of this work is the search for new magneto-cooling manganites with a large work area. It is therefore directly in line with this environmental and economic challenge, which aims to replace conventional refrigeration systems in the near future. Our objective is to identify manganites having $\mathrm{Nd}_{0.67} \mathrm{~Pb}_{0.33} \mathrm{Mn}_{0.9} \mathrm{Al}_{0.1} \mathrm{O}_{3}$ compositions synthesized using sol-gel method. We report the influences of sintering temperature on their structural, magnetic, magnetocaloric, and critical behaviors.

\section{Experimental}

To prepare $\mathrm{Nd}_{0.67} \mathrm{~Pb}_{0.33} \mathrm{Mn}_{0.9} \mathrm{Al}_{0.1} \mathrm{O}_{3}$ manganites, we have used the sol-gel method. This method is based on the use of citric acid as a complexing agent and ethylene glycol as polymerization agent. To synthesize our samples, we have used stoichiometric proportions of $\left[\mathrm{Nd}\left(\mathrm{NO}_{3}\right)_{3} \cdot 6 \mathrm{H}_{2} \mathrm{O}\right],\left[\mathrm{Pb}\left(\mathrm{NO}_{3}\right)_{2}\right], \quad\left[\mathrm{Mn}\left(\mathrm{NO}_{3}\right)_{3} \cdot 4 \mathrm{H}_{2} \mathrm{O}\right]$ and $\left[\mathrm{Al}\left(\mathrm{NO}_{3}\right)_{3} \cdot 9 \mathrm{H}_{2} \mathrm{O}\right]$ nitrates. These nitrates were firstly dissolved in distilled water, and the solution was subjected to thermal stirring at $90{ }^{\circ} \mathrm{C}$. Thereafter, we have carefully added amounts of ammonia in order to adjust the $\mathrm{pH}$ of the solution to about 7 . After a certain time (about $4 \mathrm{~h}$ ), a viscous liquid (gel) is formed. This gel has been dried at $200{ }^{\circ} \mathrm{C}$ (for $6 \mathrm{~h}$ ) in an oven in order to eliminate the residual solvent. The obtained precursor is then finely ground and the resulting powder undergoes to some cycles of grinding, pelleting and sintering. Finally, the powder was divided into two portions and then ground to sinter for $24 \mathrm{~h}$ at $900^{\circ} \mathrm{C}$ and $1100{ }^{\circ} \mathrm{C}$, separately. As an abbreviation, throughout this manuscript, we refer to the $\mathrm{Nd}_{0.67} \mathrm{~Pb}_{0.33} \mathrm{Mn}_{0.9} \mathrm{Al}_{0.1} \mathrm{O}_{3}$ samples sintered at $900{ }^{\circ} \mathrm{C}$ and $1100^{\circ} \mathrm{C}$, as $\mathrm{S} 900$ and $\mathrm{S} 1100$ respectively. 
X-ray Diffraction (XRD) pattern has been registered using "Panalytical X'Pert Pro System" two-circle automatic diffractometer operating at copper wavelength $(\lambda=1.5406 \AA)$ with a filter of Nickel to eliminate the $K_{\beta}$ ray. The measurement was made in Bragg Brentano geometry in a divergent beam, with $0.017^{\circ}$ step and 18 s counting time per step in angular range of $10 \leq 2 \theta \leq 100^{\circ}$. Rietveld method using FullProf software was used for structural parameters determination [20]. To record the magnetization measurements, a linear extraction magnetometer was used. Two types of magnetic measurements were made: (i) $M(T)$ curve was measured at FC (field cooling) modes under a weak magnetic field $\left(\mu_{0} H=0.05 \mathrm{~T}\right)$ in the temperature range of $5 \mathrm{~K} \leq T \leq 250 \mathrm{~K}$; and (ii) to access the variation of the magnetic entropy change and critical behavior for the samples, the $M\left(\mu_{0} H, T\right)$ isothermal magnetizations were taken as a function of temperature near $T_{C}$ in $0 T \leq \mu_{0} H \leq 5 T$ magnetic field interval.

\section{Results and discussion}

The obtained XRD diffractograms for S900 and S1100 are shown in Fig. 1. The compounds are good crystallized and the majority phase is a perovskite whose diffraction peaks are indexed in $R \overline{3} c$ rhombohedral symmetry. With increasing the sintering temperature,

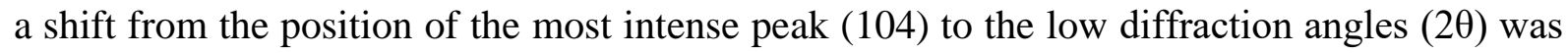
observed. This is an indication of the change of the lattice parameters with sintering temperature. The structural refinement for the samples is illustrated in Fig. 2, and the refined structural parameters are listed in Table 1. With increasing the sintering temperature, it is shown that the lattice constants and the unit cell volume of S900 and S1100 increase monotonously; however the $d_{M n, A l-O}$ distances decrease. This behavior agrees well with that found in other previous works [21-23]. The average crystallite size is estimated using Scherer formula as [24]:

$D=\frac{0.9 \lambda}{\beta \cos (\theta)}$ 
where $\lambda$ is the employed X-ray wavelength, $\theta$ is the diffraction angle for the most intense peak, and $\beta=\sqrt{\beta_{x}^{2}-\beta_{\text {inst }}^{2}}$ its FWHM (full width at half maximum) with $\beta_{x}$ is the experimental FWHM, and $\beta_{\text {inst }}$ is the FWHM of a standard silicon sample. The obtained $D$ values are listed in Table $\mathbf{1}$ and show a clearly rise with increasing sintering temperature, in agreement with other previously works reported in the literature $[\mathbf{2 5}, \mathbf{2 6}]$.

Fig. 3 shows the $M(T)$ data taken at FC mode under magnetic field of $\mu_{0} H=0.05 \mathrm{~T}$ for S900 and S1100. The $M(T)$ measurement shows a FM-PM phase transition towards the Curie temperature $\left(T_{C}\right)$ which is identified as the minimum of $d M / d T$ curve (inset of Fig. 3). The FM-PM phase transitions occur at $130 \mathrm{~K}$ for S900 and $155 \mathrm{~K}$ for S1100. In addition, the magnetization amplitude in the FM-region is higher for S1100 than that of S900. This increase in both $M$ and $T_{C}$ values is related to the increase of crystallite size. Indeed, according to the core/surface morphology, the arrangement of the spins on the surface is smaller than that of the core. Surface is considered as magnetically dead layer, with random disorder. Therefore, as the crystallite size increases with sintering temperature, this nonmagnetic surface layer decreases and, therefore, the core / shell thickness ratio increases. This leads to the elimination of surface effects (broken exchange bonds, spin-canting) and, consequently, an improvement of the $M$ and $T_{C}$ values has been observed [11].

To estimate the isothermal variation of magnetic entropy $\left(\Delta S_{m}\right)$ we used the isothermal magnetizations curves $M\left(H, \mu_{0} H\right)$ performed at temperatures around $T_{C}$ as shown in Fig. 4. With similar behavior to $M(T)$ curve, the $M\left(\mu_{0} H, T\right)$ isotherms gradually decrease with increasing temperature. In addition, when $\mu_{0} H$ increases, the $M$ values increase non-linearly in the low temperature range, and vary linearly at high temperature. The $\Delta S_{m}$ values were calculated by the application of the following Maxwell relation [1]:

$\Delta S_{m}\left(T, \Delta \mu_{0} H\right)=\int_{0}^{\mu_{0} H}\left(\frac{\partial M}{\partial M}\right)_{H} d H$ 
where $\mu_{0} H$ is the applied magnetic field. The results obtained for applied fields of 1 to $5 \mathrm{~T}$ are shown in Fig. 5 for S900 and S1100. As expected for a ferromagnetic material, the magnetic entropy variations are negative and reach a minimum peak near the order temperatures. The $\Delta S_{m}$ reaches the maximum values of 3.23 and $4.41 \mathrm{~J} / \mathrm{kg} . \mathrm{K}$ at $\Delta \mu_{0} H=5 \mathrm{~T}$ for $\mathrm{S} 900$ and $\mathrm{S} 1100$, respectively. This variation of magnetic entropy changes with sintering temperature was observed previously $[\mathbf{2 7}, \mathbf{2 8}]$. The relative cooling power $(\mathrm{RCP})$ of a material is defined as the integrated area under the $\Delta S_{m}(T)$ curve with the temperatures corresponding to the half-height values of the magnetic entropy variation peak $(\delta T)$ as bounds of integration. The RCP values at different applied fields are estimated according the following relation [1]:

$R C P=\left|\Delta S_{M}^{\max }\right| \times \delta T_{F W H M}$

For $\Delta \mu_{0} H=5 \mathrm{~T}$, the RCP values are estimated respectively as 242 and $245 \mathrm{~J}_{\mathrm{Kg}} \mathrm{Kg}^{-1}$ for $\mathrm{S} 900$ and S1100. These values are significantly higher. This allows us to conclude that our samples can be considered as potential candidates in the cooling power technology. In addition, the obtained values are quite comparable to those of other manganite systems [10-16].

In Fig. 6, we have presented the $M^{2} v s . \mu_{0} H / M$ (called as the Arrott plots) [29] which show positive slopes near some temperatures around $T_{C}$ values. According to Banerjee's criterion [30], these positive slopes of $M^{2} v s . \mu_{0} H / M$ suggest that $S 900$ and $S 1100$ samples have the character of second-order phase transitions. In order to study the critical behavior for S900 and S1100 near their $T_{C}$ temperatures, we conducted an investigation of their critical exponents $(\beta, \gamma$ and $\delta)$. Depending on the mean field theory [31], the Arrott curves $\left(M^{2} v s\right.$. $\left.\mu_{0} H / M\right)$ given in Fig. 6 would present around $T_{C}$ as straight lines and the isotherm at $T=T_{C}$ should pass through the origin. From Fig. 6, these two conditions are more accurate for S900 and have not reached for S1100. This reveals that the mean field model is the suitable one to describe the critical behaviour of $\mathrm{S} 900$. As a result, to estimate the critical $\beta$ and $\gamma$ exponents 
for S1100 we used so-called modified Arrott plots (MAPs) by building the $M^{1 / \beta} v s .\left(\mu_{0} H / M\right)^{1 / \gamma}$ plots using the following three models [32, 33]:

(i) 3D-Heisenberg model $(\beta=0.365, \gamma=1.336$ and $\delta=4.8)$.

(ii) 3D-Ising model $(\beta=0.325, \gamma=1.24$ and $\delta=4.82)$.

(iii) Tricritical mean-field model $(\beta=0.25, \gamma=1$ and $\delta=5)$.

These three models were used to draw the MAPs for S1100 sample, and the conditions that the isotherms are parallel around $T_{C}$, and the $T_{C}$-isotherm passes through origin are more accurate in the case of the 3D-Heisenberg model (see Fig. 7). From Fig. 6 (for S900) and Fig. 7 (for S1100), the linear extrapolation of the data by intersection with the $M^{1 / \beta}$-axis determines the spontaneous magnetization $M_{s}$ (below $T_{C}$ ) and the linear extrapolation by intersection with $\left(\mu_{0} H / M\right)^{1 / \gamma_{-}}$axis allows to determine the values of the inverse initial susceptibility $\chi 0^{-1}$ (above $T_{C}$ ). Then, the data of $M_{S}(T)$ and $\chi 0^{-1}(T)$ were respectively adjusted in Fig. 8 using the two following equations.

$$
\begin{aligned}
& M_{S}(T)=M_{0}(-\varepsilon)^{\beta} \quad\left(\text { with } \varepsilon<0 \text { and } T<T_{C}\right) \\
& \chi_{0}^{-1}(T)=\left(\frac{h_{0}}{M_{0}}\right) \varepsilon^{\gamma} \quad\left(\text { with } \varepsilon>0 \text { and } T>T_{C}\right)
\end{aligned}
$$

where $M_{0}$, and $h_{0} / M_{0}$ designate the critical amplitudes, and $\varepsilon=\left(T-T_{C}\right) / T_{C}$ is the reduced temperature. The fitting results are shown in Fig. 8 for S900 and S1100 respectively, and the estimated values of $\beta$ and $\gamma$ agree well with those obtained from the MAP of Fig. 6 (for S900) and Fig. 7 (for S1100). Another estimation of the exponents $\beta$ and $\gamma$ can be achieved more exactly using the Kouvel-Fisher (KF) method according the following equations $[\mathbf{3 4}, \mathbf{3 5}]$ :

$$
\begin{aligned}
& M_{S}(T)\left[\frac{d M_{S}(T)}{d T}\right]^{-1}=\frac{\left(T-T_{C}\right)}{\beta} \\
& \chi_{0}^{-1}(T)\left[\frac{d \chi_{0}^{-1}(T)}{d T}\right]^{-1}=\frac{\left(T-T_{C}\right)}{\gamma}
\end{aligned}
$$


Fig. 9 shows the $M_{S}(T)\left[\frac{d M_{S}(T)}{d T}\right]^{-1}$ vs. $T$ and $\chi_{0}^{-1}(T)\left[\frac{d \chi_{0}^{-1}(T)}{d T}\right]^{-1}$ vs. $T$ curves for $\mathrm{S} 900$ and S1100 respectively. The linear adjustments of these plots using Eqs. (6) and (7) allowed us to determine the $\beta$ and $\gamma$ values which are very close to those found in Fig. 6 (for S900) and Fig. 7 (for S1100). Concerning the third exponent $(\delta)$, it is possible to obtain it directly by adjusting the critical isotherm $(\mathrm{CI}), M\left(T_{C}, \mu_{0} H\right)$, according this relation:

$$
M=D\left(\mu_{0} H\right)^{1 / \delta} \quad \text { (with } \varepsilon=0 \text { and } T=T_{C} \text { ) }
$$

As illustrated in Fig. 9, we found $\delta=3.25 \pm 0.013$ and $\delta=4.69 \pm 0.017$ for S900 and S1100 respectively. These values can be checked and confirmed form the $\beta$ and $\gamma$ values previously determined according to Widom relation given as [36]:

$$
\delta=1+\frac{\gamma}{\beta}
$$

This equation gives $(\delta=3.26$ and $\delta=4.772$ respectively for S900 and S1100) and $(\delta=3.27$ and $\delta=4.71$ respectively for S900 and S1100) when the values of $\beta$ and $\gamma$ are taken respectively from Fig. 8 and 9. These values correlate well with the $\delta$ values estimated from the CI. This result confirms the well estimation of the critical exponents of the present samples. In Table 2, we have compared the critical exponents for S900 and S1100, respectively (present work) with those of the theoretical models [32, 34]. As shown in the table, the critical exponents are close to those of the mean-field and the 3D-Heisenberg models for S900 and S1100, respectively. In particular, by comparing the values found for our compounds, we can notice that the value of $\beta$ decreases however the $\gamma$ and $\delta$ values increase as the sintering temperature increases. A similar behavior was observed in other works $[\mathbf{3 7}, \mathbf{3 8}]$. On the other hand, the universality class of the magnetic phase transition depends on the exchange interaction range as shown by the equation of the exchange integral [34]:

$$
J(r)=1 / r^{d+\sigma}
$$


where $d$ designed the dimension of the system, and $\sigma$ represents the range of interaction. It has been demonstrated that the 3D-Heisenberg exponents $(\beta=0.365, \gamma=1.336, \delta=4.8)$ are valid if $\sigma \geq 2$, the mean- field exponents $(\beta=0.5, \gamma=1$ and $\delta=3$ ) occur if $\sigma$ is less than $3 / 2$, however for the intermediate range $3 / 2<\sigma<2$, the exponents belong to different universality classes which depends upon $\sigma$. In the case of our work, the values of $(\beta, \gamma$ and $\delta$ ) exponents are close to those of the mean-field and the 3D-Heisenberg models respectively for S900 and S1100. So the exchange interaction $J(r)$ ranges as $J(r)<r^{-5}$ for S900 (respectively $J(r)$ decays slower than $r^{-5}$ for $\left.\mathrm{S} 1100\right)$.

\section{Conclusion}

$\mathrm{Nd}_{0.67} \mathrm{~Pb}_{0.33} \mathrm{Mn}_{0.9} \mathrm{Al}_{0.1} \mathrm{O}_{3}$ manganites have been prepared at $900^{\circ} \mathrm{C}$ and $1100^{\circ} \mathrm{C}$. XRD measurements show that the compounds are good crystallized and their majority phases are perovskites whose diffraction peaks are well indexed in the $R \overline{3} c$ rhombohedral symmetry. The $M(T)$ measurements show second order FM-PM magnetic phase transitions at Curie temperature equal to $130 \mathrm{~K}$ and $155 \mathrm{~K}$ for S900 and S1100, respectively. The isothermal variations of magnetic entropy $\Delta S_{m}$ were calculated from the experimental $M\left(\mu_{0} H, T\right)$ isothermal magnetizations curves. The critical exponents are close to those of the mean-field theory for S900; however for S1100 they are close to the 3D-Heisenberg model.

\section{Acknowledgements}

This work was supported by the Deanship of Scientific Research at Sattam Bin Abdulaziz University under the research Project Number 2017/01/7246. 


\section{References}

[1] M.H. Phan, S.C. Yu, J. Magn. Magn. Mater. 308 (2007) 325.

[2] O. Tegus, E. Bruck, K.H.J. Buschow, F.R. de Boer, Nature 415 (2002) 150.

[3] V. Provenzano, A.J. Shapiro, R.D. Shull, Nature 429 (2004) 853.

[4] K.A. Gschneidner Jr, V.K. Pecharsky, A.O. Tsokol, Rep. Prog. Phys. 68 (2005) 1479.

[5] A. De Campos, D.L. Rocco, A.M.G. Carvalho, L. Caron, A.A. Coelho, S. Gama, L.M. Da Silva, F.C.G. Gandra, A.O. Dos Santos, L.P. Cardoso, P.J. Von Ranke, N.A. De Oliveira, Nat. Mater. 5 (2006) 802.

[6] V.K. Pecharsky, K.A. Gschneidner Jr, J. Magn. Magn. Mater. 200 (1999) 44.

[7] A. Rowe, A. Tura, Int. J. Refrig. 29 (2006) 1286.

[8] O. Gutfleisch, M. A. Willard, E. Brück, C.H. Chen, S.G. Sankar, J.P. Liu Adv. Mater. 23 (2011) 821.

[9] L.T. Kuhn, N. Pryds, C.R.H. Bahl, A. Smith, J. Phys.: Conf. Ser. 303 (2011) 012082.

[10] S. Hcini, M. Boudard, S. Zemni, M. Oumezzine, Ceram. Int. 40 (2014) 16041.

[11] E. Oumezzine, S. Hcini, E.K. Hlil, E. Dhahri, M. Oumezzine, J. Alloys Compd. 615 (2014) 553.

[12] K. Riahi, I. Messaoui, W.C. Koubaa, S. Mercone, B. Leridon, M. Koubaa, A. Cheikhrouhou, J. Alloys Compd. 688 (2016) 1028.

[13] S. Mahjoub, M. Baazaoui, E.K. Hlil, M. Oumezzine, Ceram. Int. 41 (2015) 12407.

[14] M.R. Laouyenne, M. Baazaoui, Kh. Farah, E.K. Hlil, M. Oumezzine. J. Magn. Magn. Mater. 474 (2019) 393.

[15] H. Ben Khlifa, R. M'nassri, W.C. Koubaa, E.K. Hlil, A. Cheikhrouhou. Ceram. Int. 43 (2017) 8709.

[16] I. Walha, M. Smari, T. Mnasri, E. Dhahri. J. Magn. Magn. Mater. 454 (2018) 190.

[17] V.P.S. Awana, R. Tripathi, S. Balamurugan, H. Kishan, E. Takayama-Muromachi, Solid State Commun. 140 (2006) 410.

[18] M.H. Phan, S.C. Yu, N.H. Hur, Appl. Phys. Lett. 86 (2005) 72.

[19] R. Jha, S.K. Singh, A. Kumar, V.P.S. Awana, J. Magn. Magn. Mater. 324 (2012) 2849.

[20] H.M. Rietveld, J. Appl. Cryst. 2 (1969) 65.

[21] J. Fang, Q. Wang, Y. Zou, X. Yu, R. Li, Y. Zhang, J. Appl. Phys. 104 (2008) 123905.

[22] T. Sarkar, B. Ghosh, A.K. Raychaudhuri, T. Chatterji, Phys. Rev. B 77 (2008) 235112.

[23] T. Zhang, M. Dressel, Phys. Rev. B 80 (2009) 014435.

[24] S. Hcini, S. Zemni, A. Triki, H. Rahmouni, M. Boudard, J. Alloys Compd. 509 (2011) 1394. 
[25] R.P. Patil, P.P. Hankare, K.M. Garadkar, R. Sasikala, J. Alloys Compd. 523 (2012) 66.

[26] M. Rahimi, P. Kameli, M. Ranjbar, H. Salamati, J. Nanopart. Res. 15 (2013) 1865.

[27] R. M'nassri, N.C. Boudjada, A. Cheikhrouhou, J. Alloys Compd. 626 (2015) 20.

[28] S.R. Lee, M.S. Anwar, F. Ahmed, B.H. Koo, Trans. Nonferrous Met. Soc. China, 24 (2014) s141.

[29] A. Arrott, Phys. Rev. 108 (1957) 1394.

[30] S.K. Banerjee, Phys. Lett. 12 (1964) 16.

[31] H.E. Stanley, Introduction to Phase Transitions and Critical Phenomena, Oxford University Press, London, 1971.

[32] S.N. Kaul, J. Magn. Magn. Mater. 53 (1985) 5.

[33] K. Huang, Statistical Mechanics, second ed., Wiley, New York, 1987.

[34] M.E. Fisher, S.K. Ma, B.G. Nickel, Phys. Rev. Lett 29 (1972) 917.

[35] J.S. Kouvel, M.E. Fisher, Phys. Rev. 136 (1964) 1626.

[36] B. Widom, J. Chem. Phys. 41 (1964) 1633.

[37] S. Hcini, N. Kouki, A. Omri, A. Dhahri, M.L. Bouazizi, J. Magn. Magn. Mater. 464 (2018) 91.

[38] H. Baaziz, A. Tozri, E. Dhahri, E.K. Hlil, Solid State Commun. 208 (2015) 45. 


\section{Tables}

Table 1: Rietveld refinement of the structural parameters for S900 and S1100. The numbers in parentheses are estimated standard deviations to the last significant digit. $B_{i s o}$ : the isotropic Debye-Waller factor; $d_{M n, A l-} O$ : bond length; $\theta_{M n, A l-O-M n, A l}$ : bond angle; $D$ : average crystallites size. Agreement factors of profile $R_{p}$, weighted profile $R_{w p}$ and structure $R_{F} \cdot \chi^{2}$ : the goodness of fit.

Table 2: Estimated critical exponents for S900 and S1100 (present work) compared with those of the standard theoretical models. 
Table 1

\begin{tabular}{|c|c|c|c|c|c|}
\hline \multicolumn{4}{|l|}{ Samples } & \multirow[t]{2}{*}{ S900 } & \multirow[t]{2}{*}{ S1100 } \\
\hline Space Group & $R \overline{\mathbf{3}} c$ & & & & \\
\hline \multirow[t]{3}{*}{ Cell parameters } & \multirow{2}{*}{\multicolumn{2}{|c|}{ Lattice constants }} & $a=b(\AA)$ & $5.5268(1)$ & $5.5291(1)$ \\
\hline & & & $c(\AA)$ & $13.4540(4)$ & $13.4716(4)$ \\
\hline & \multicolumn{2}{|c|}{ Cell volume } & $V\left(\AA^{3}\right)$ & $356.13(1)$ & $356.62(2)$ \\
\hline \multirow[t]{12}{*}{ Atoms } & \multirow[t]{4}{*}{$N d / P b$} & \multirow{3}{*}{$\begin{array}{l}\text { Atomic } \\
\text { Positions }\end{array}$} & $x$ & 0 & 0 \\
\hline & & & $y$ & 0 & 0 \\
\hline & & & $z$ & $1 / 4$ & $1 / 4$ \\
\hline & & \multicolumn{2}{|l|}{$B_{\text {iso }}\left(\AA^{2}\right)$} & $0.55(4)$ & $0.40(3)$ \\
\hline & \multirow[t]{4}{*}{$M n / A l$} & \multirow{3}{*}{$\begin{array}{l}\text { Atomic } \\
\text { Positions }\end{array}$} & $x$ & 0 & 0 \\
\hline & & & $y$ & 0 & 0 \\
\hline & & & $z$ & 0 & 0 \\
\hline & & \multicolumn{2}{|l|}{$B_{\text {iso }}\left(\AA^{2}\right)$} & $0.63(4)$ & $0.31(4)$ \\
\hline & \multirow[t]{4}{*}{$O$} & Atomic & $x$ & $0.495(2)$ & $0.467(3)$ \\
\hline & & \multirow[t]{2}{*}{ Positions } & $y$ & 0 & 0 \\
\hline & & & $z$ & $1 / 4$ & $1 / 4$ \\
\hline & & \multicolumn{2}{|l|}{$\boldsymbol{B}_{\text {iso }}\left(\AA^{2}\right)$} & $1.49(5)$ & $1.50(0)$ \\
\hline \multirow{3}{*}{$\begin{array}{l}\text { Structural } \\
\text { parameters }\end{array}$} & \multicolumn{3}{|c|}{$d_{M n, A l-o}(\AA)$} & $1.958(9)$ & $1.951(2)$ \\
\hline & \multicolumn{3}{|c|}{$\theta_{M n, A l-O-M n, A l}\left(^{\circ}\right)$} & $170.3(4)$ & $178.38(1)$ \\
\hline & \multicolumn{3}{|c|}{$D(n m)$} & 52 & 65 \\
\hline \multirow{4}{*}{$\begin{array}{l}\text { Agreement } \\
\text { factors }\end{array}$} & \multicolumn{3}{|l|}{$R_{p}(\%)$} & 1.49 & 1.45 \\
\hline & \multicolumn{3}{|l|}{$R_{w p}(\%)$} & 2.09 & 1.98 \\
\hline & \multicolumn{3}{|l|}{$\boldsymbol{R}_{F}(\%)$} & 2.02 & 2.62 \\
\hline & \multicolumn{3}{|l|}{$\chi^{2}(\%)$} & 2.45 & 2.33 \\
\hline
\end{tabular}


Table 2

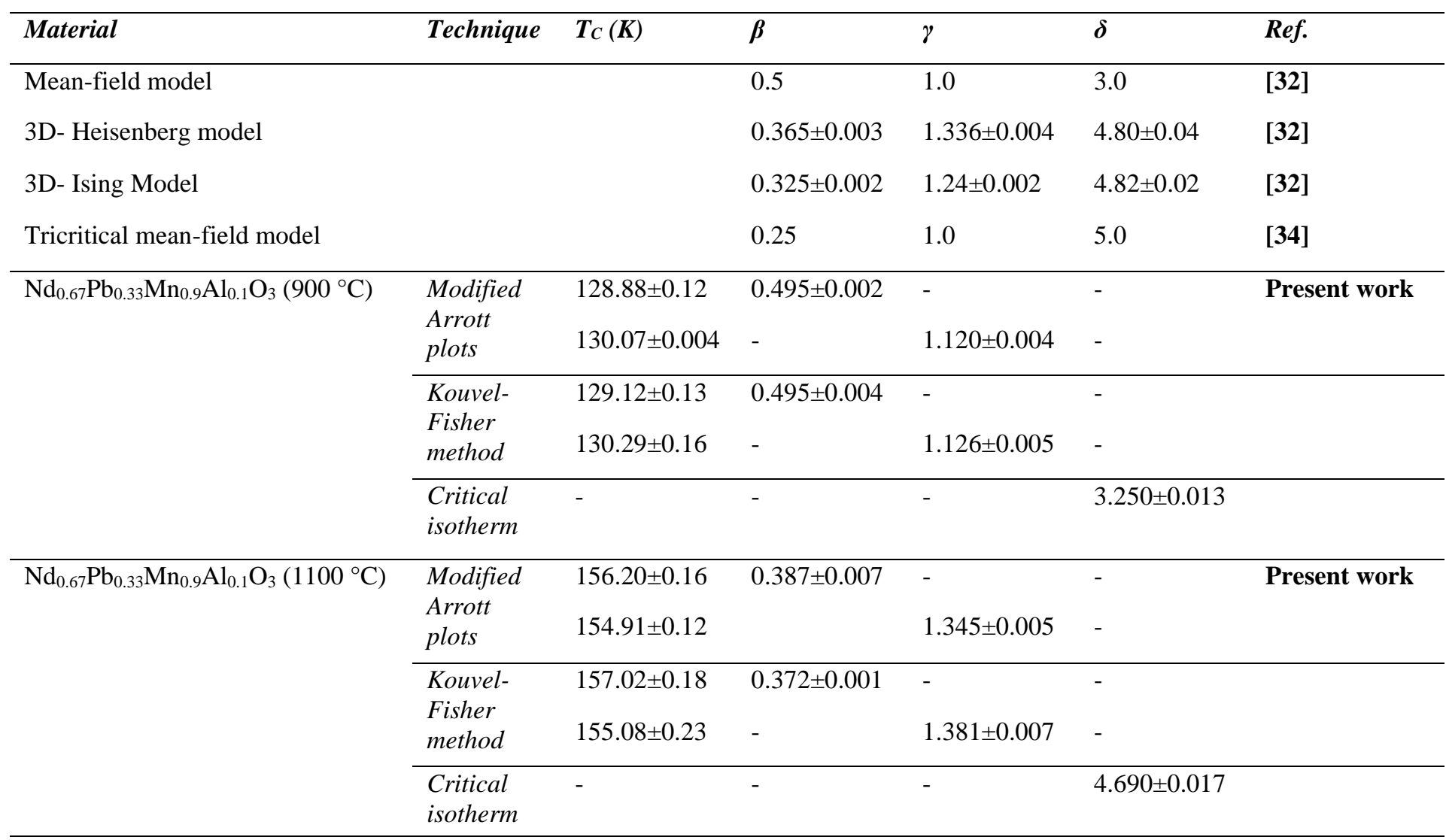


Figure captions

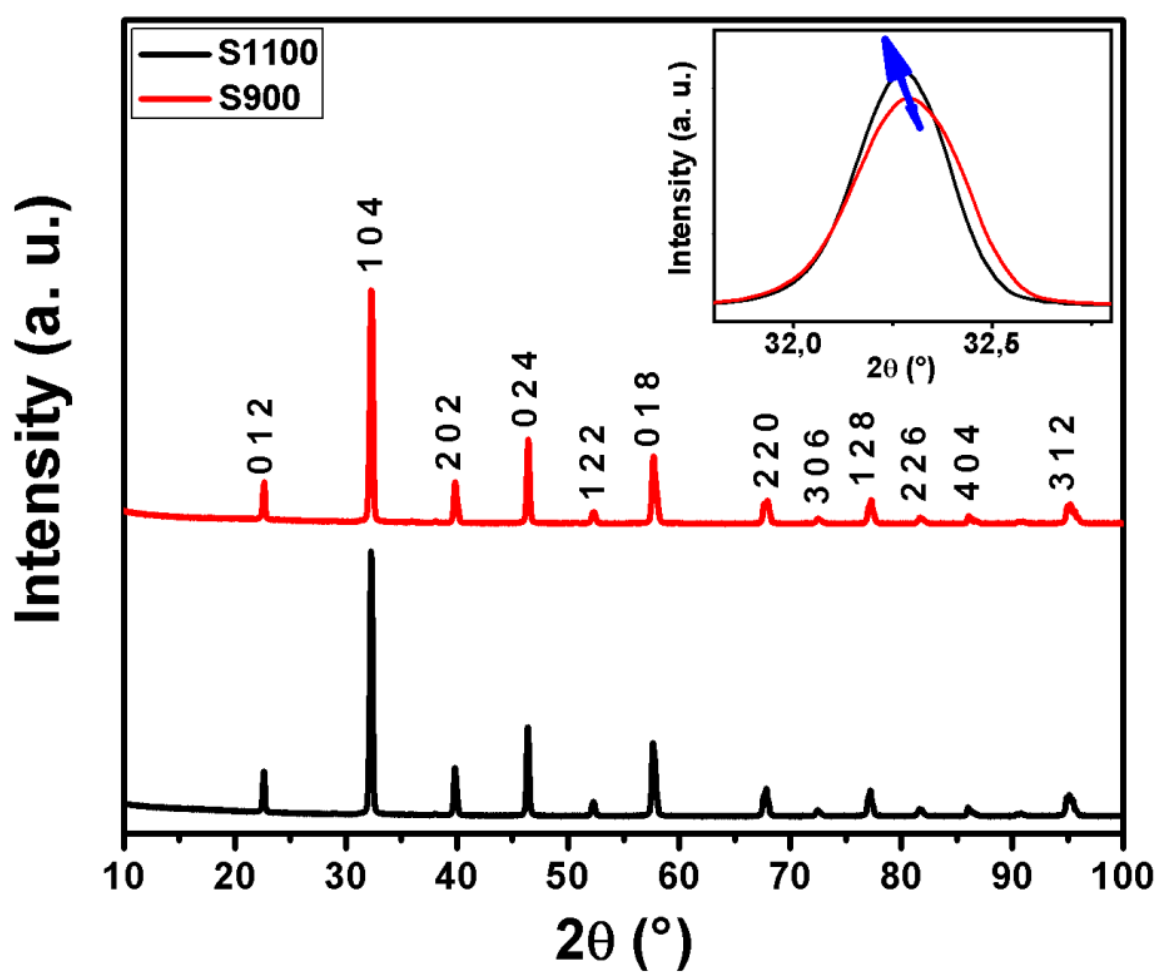

Fig. 1: X-ray diffraction patterns for S900 and S1100. All peaks of the perovskite phases are indexed in the hexagonal setting of the rhombohedral $R \overline{3} c$ symmetry. 


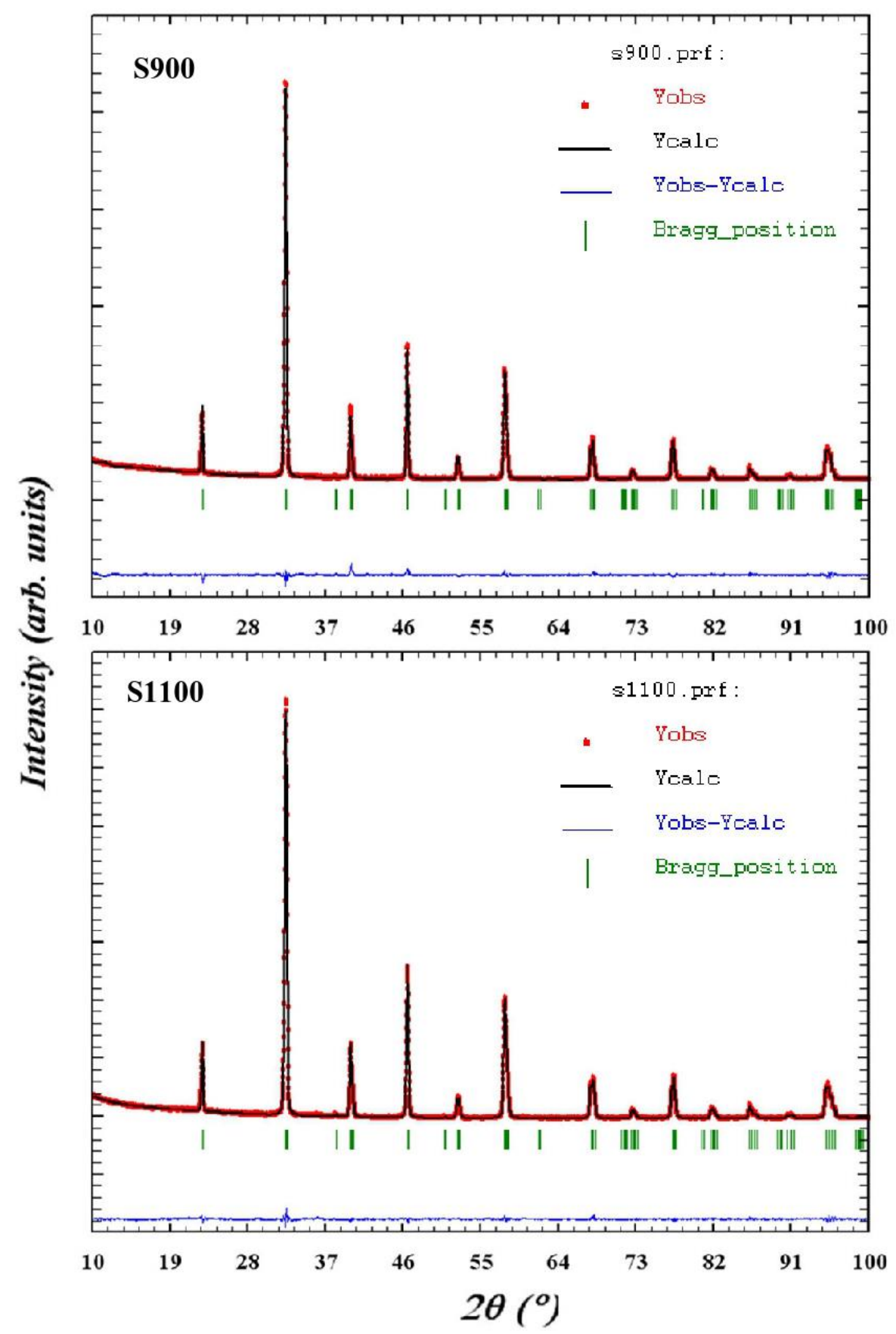

Fig. 2: Rietveld analysis of XRD patterns for S900 and S1100. The bottom line (blue) represents the difference between the XRD data (red) and calculated fit (black), and the green lines are Bragg positions. 


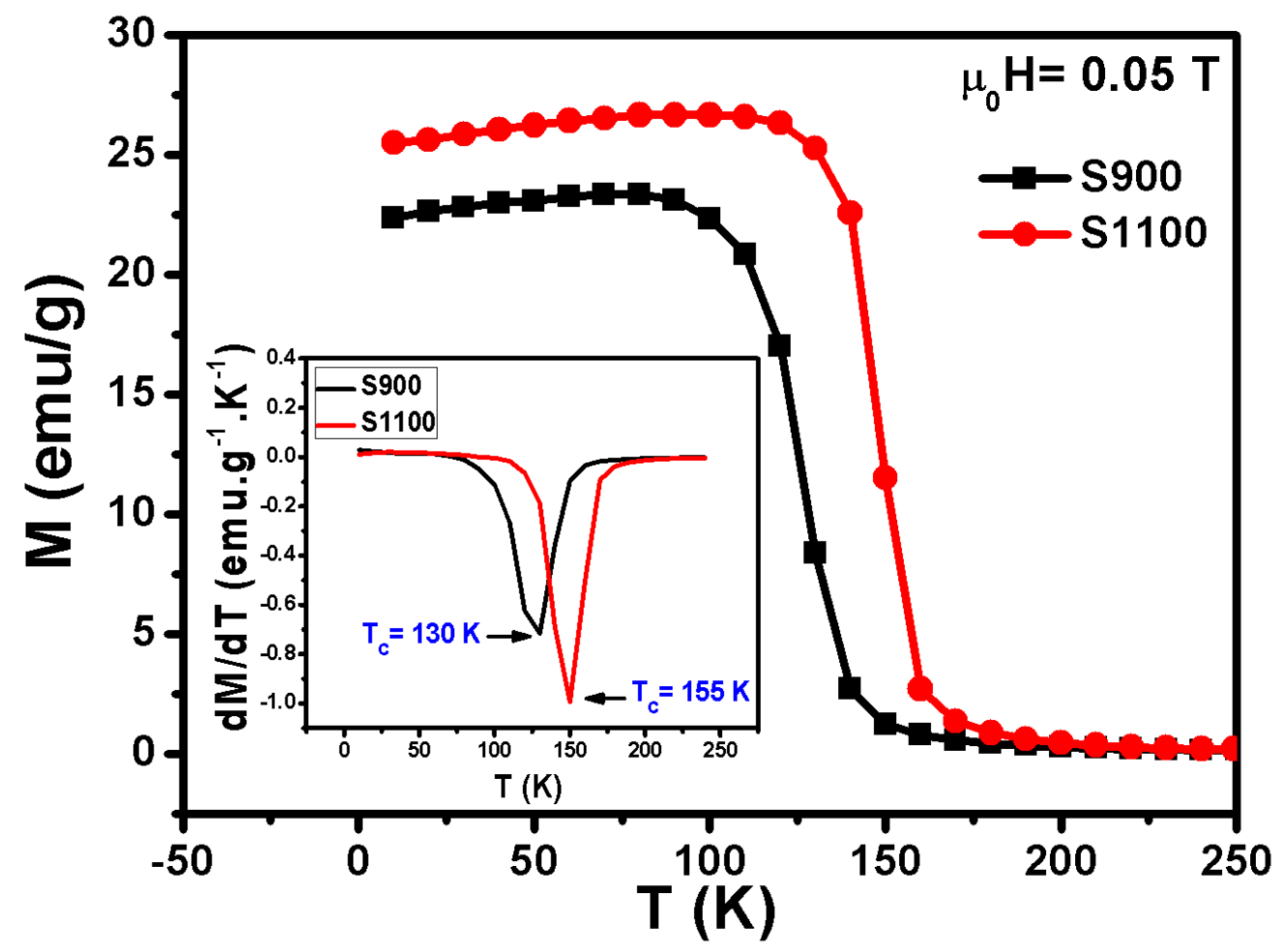

Fig. 3: Temperature dependence of magnetization and graph of $d M / d T v s$. $T$ under magnetic field of $\mu_{0} H=0.05 \mathrm{~T}$ for $\mathrm{S} 900$ and $\mathrm{S} 1100$. 

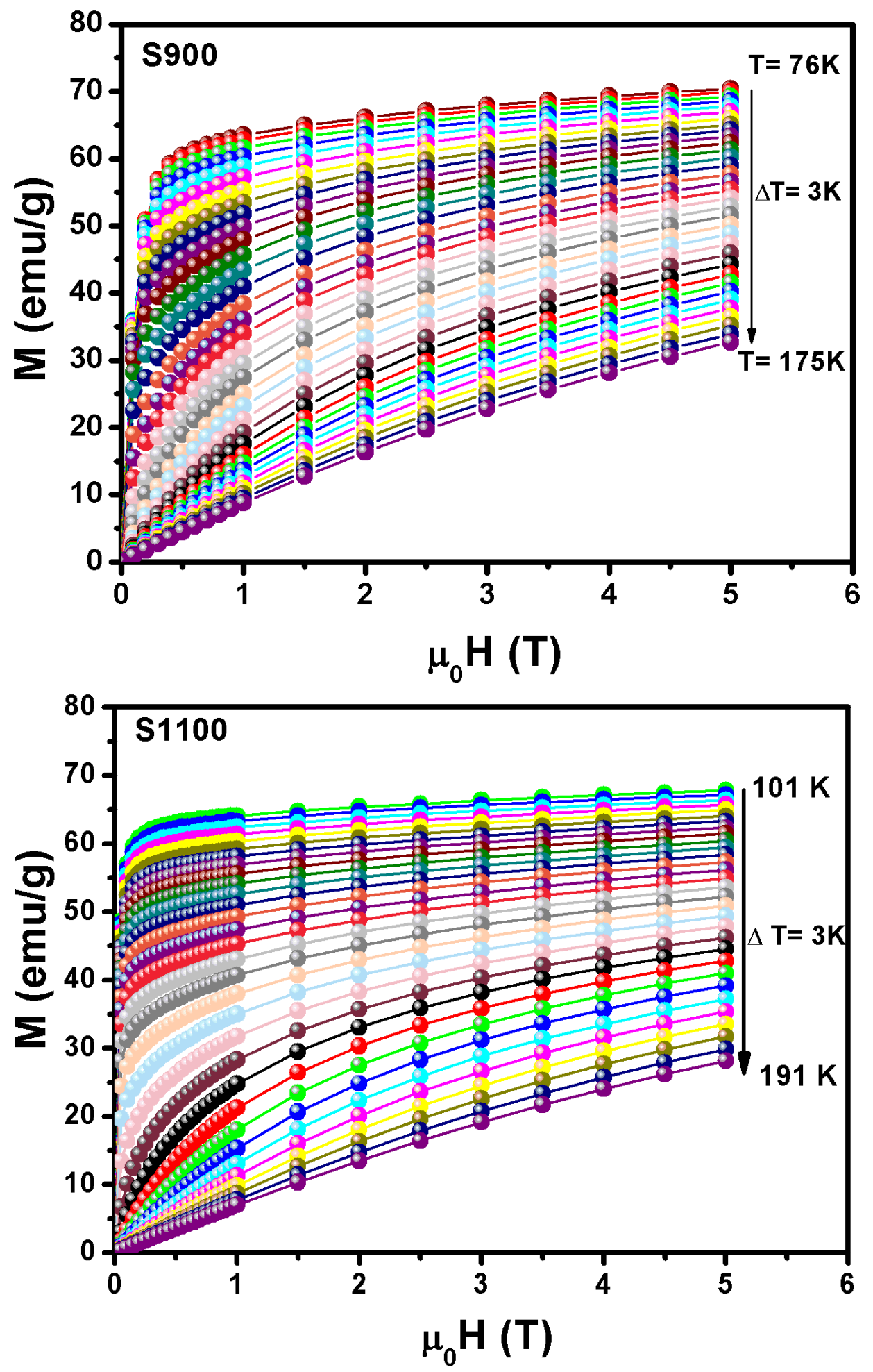

Fig.4: $M\left(\mu_{0} H, T\right)$ curves for S900 and S1100. 

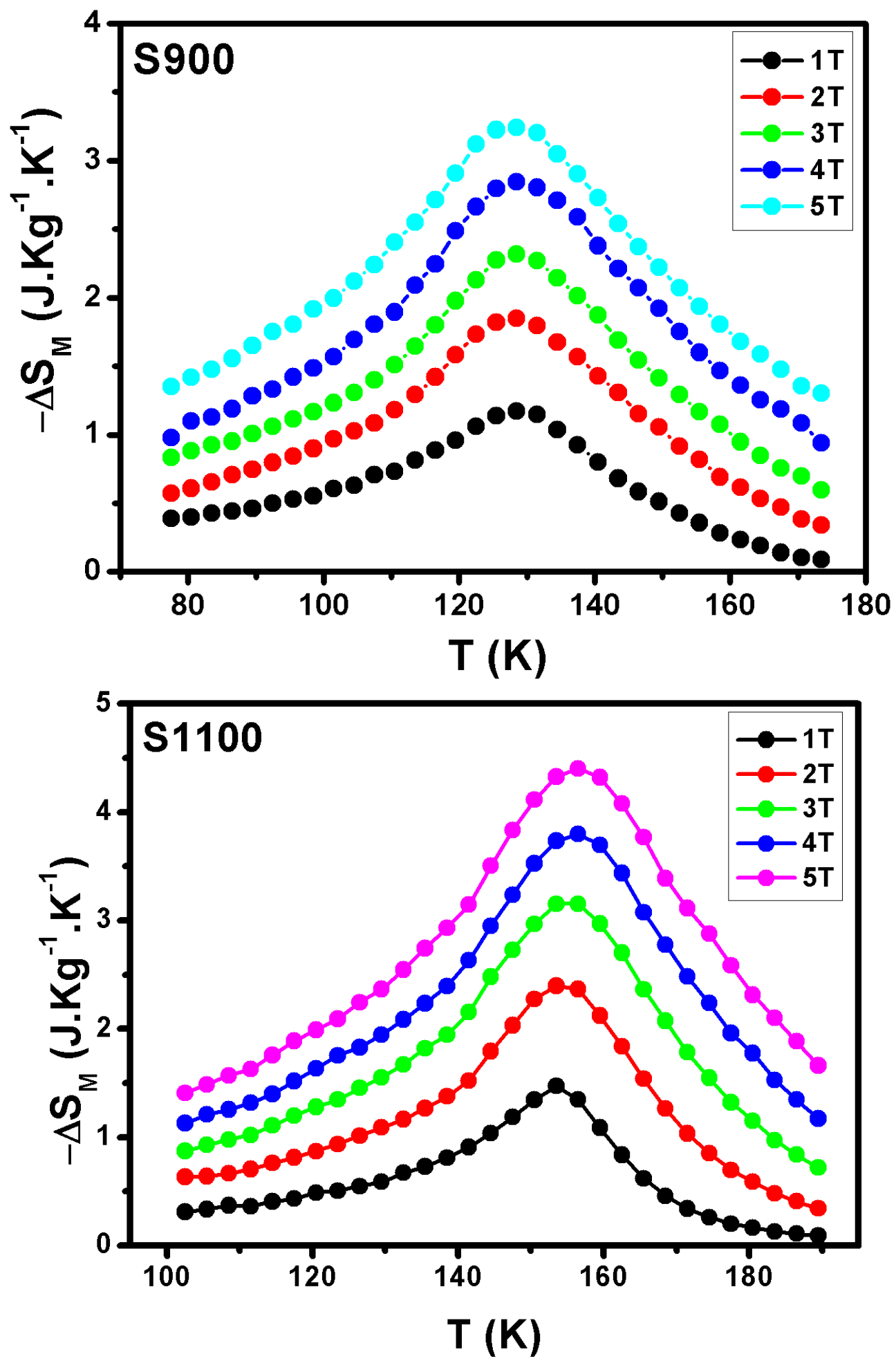

Fig.5: Temperature dependence of the magnetic entropy change at various applied magnetic fields for S900 and S1100. 

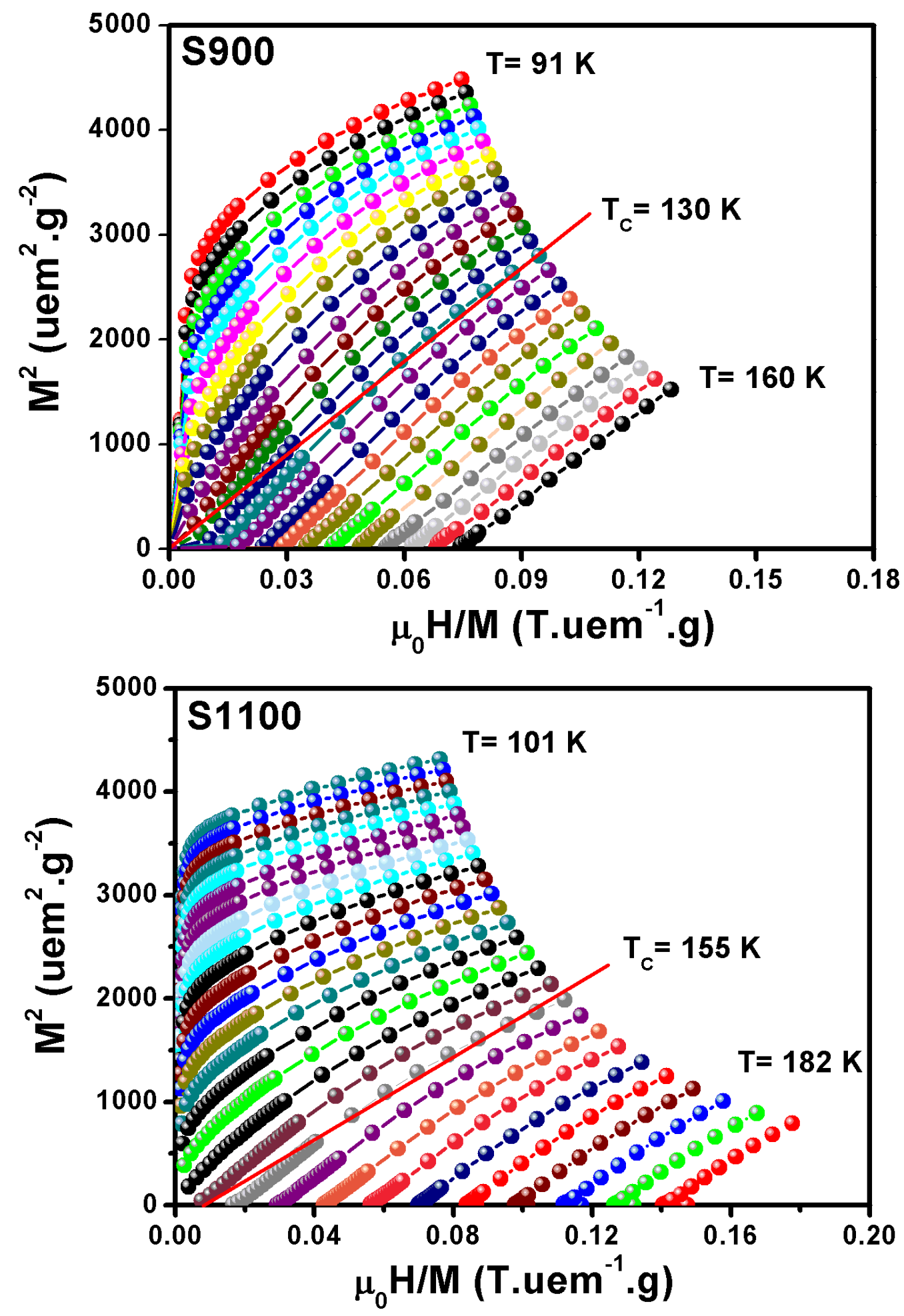

Fig.6: Arrott plots around $T_{C}$ for $\mathrm{S} 900$ and $\mathrm{S} 1100$. 


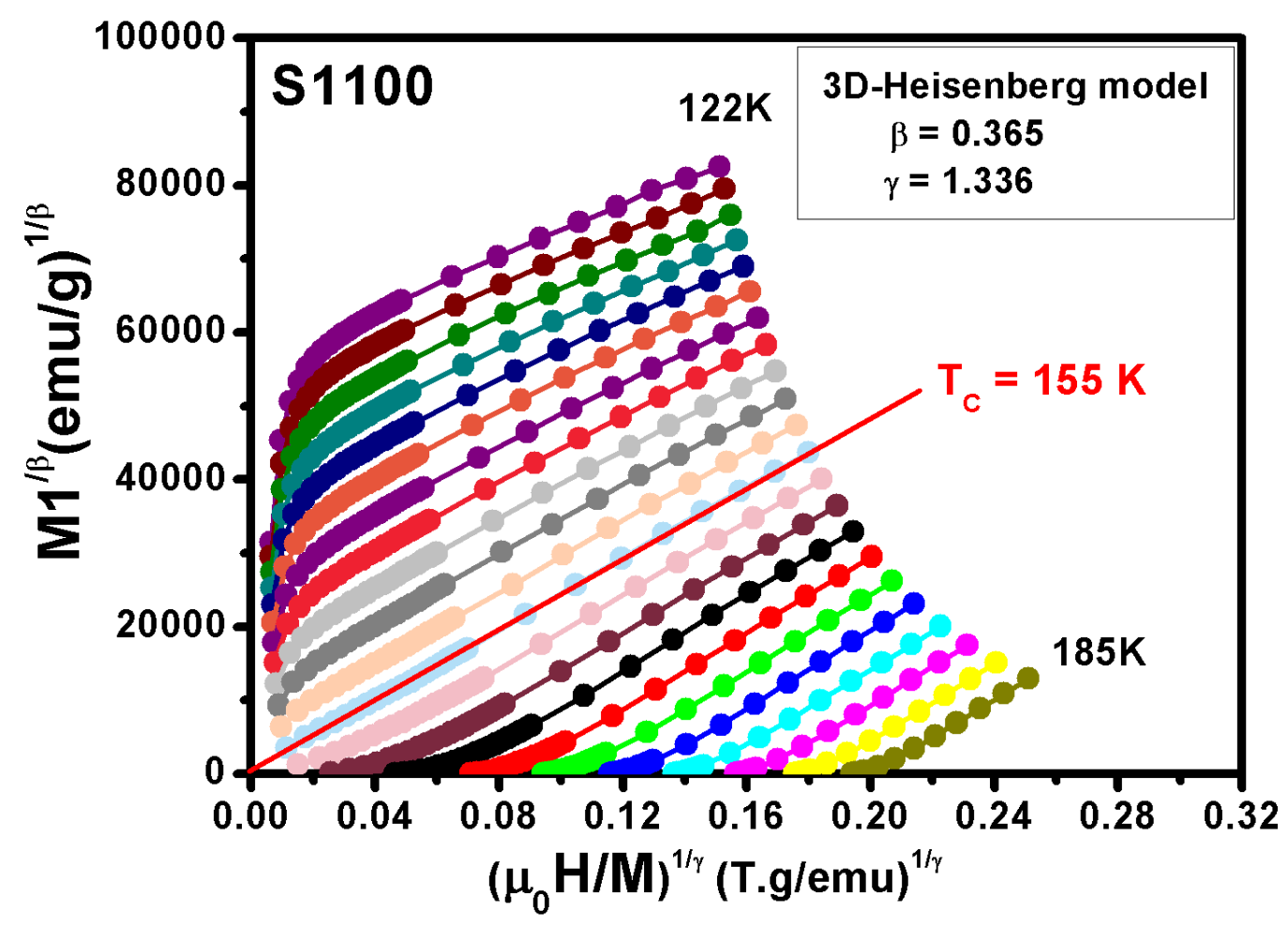

Fig. 7: Modified Arrott plots (MAP): isotherms of $M^{1 / \beta}$ vs. $\left(\mu_{0} H / M\right)^{1 / \gamma}$ for $\mathrm{S} 1100$ according to the 3D-Heisenberg model $(\beta=0.365, \gamma=1.336)$. 

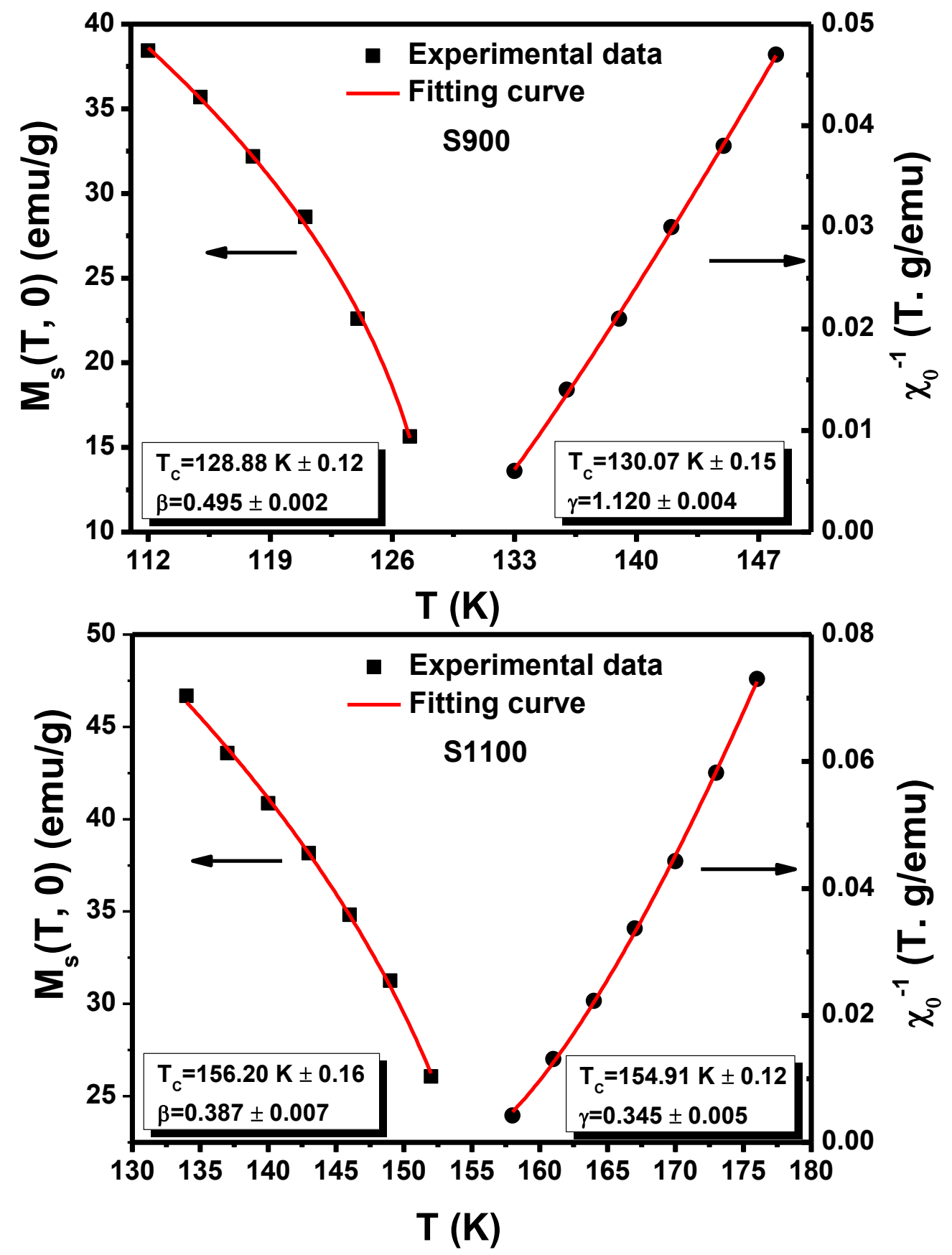

Fig.8: Spontaneous magnetization $M_{s}(T)$ (left-axis) and the inverse initial susceptibility $\chi 0^{-1}(T)$ (right-axis) as a function of temperature for S900 and S1100. Red solid lines are the fits according to Eqs. (4) and (5), respectively. 

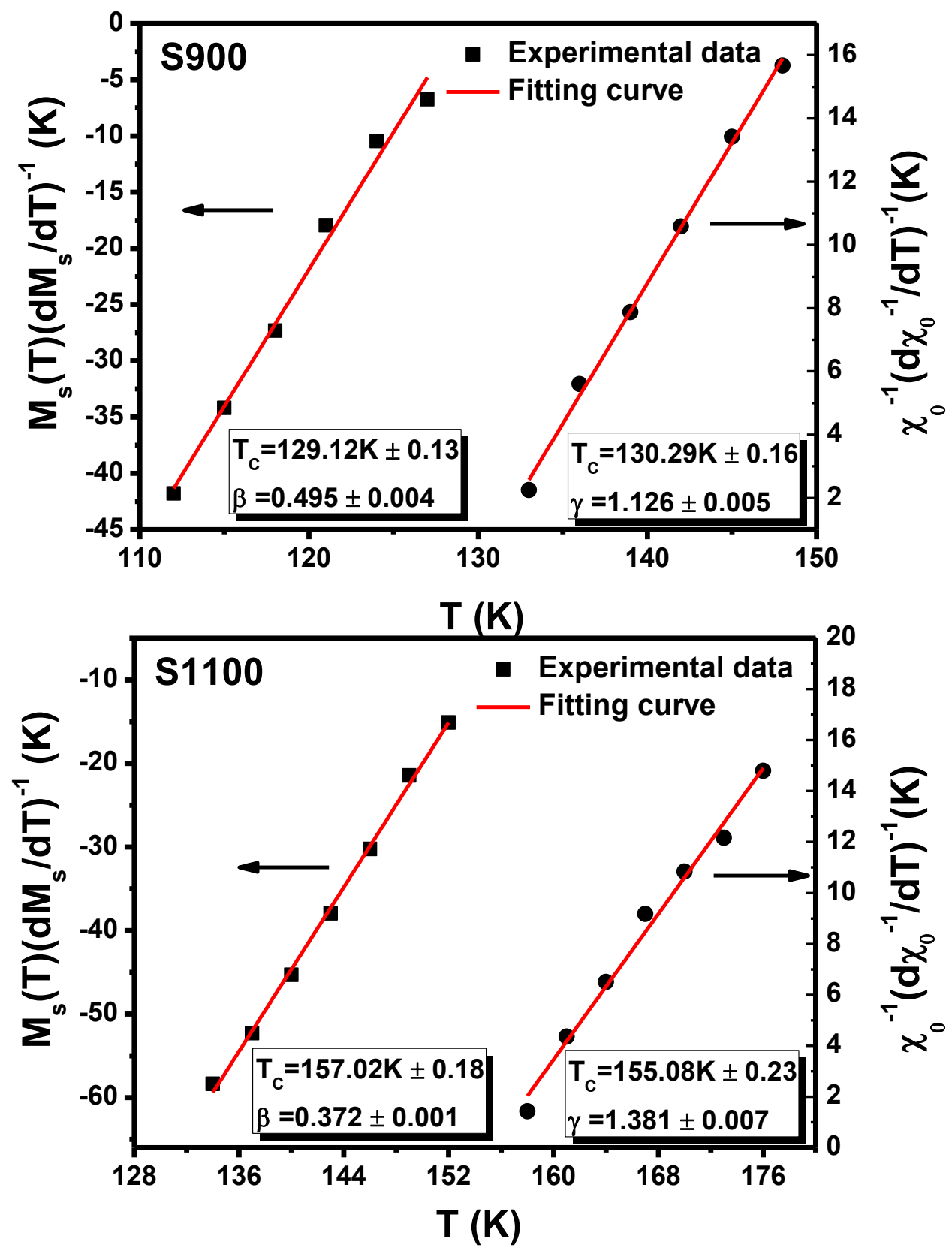

Fig.9: Kouvel-Fisher plots for the spontaneous magnetization $M_{s}(T)$ (left-axis) and the inverse initial susceptibility $\chi 0^{-1}(T)$ (right-axis) as a function of temperature for S900 and S1100. Red solid lines are the fits according to Eqs. (6) and (7), respectively. 

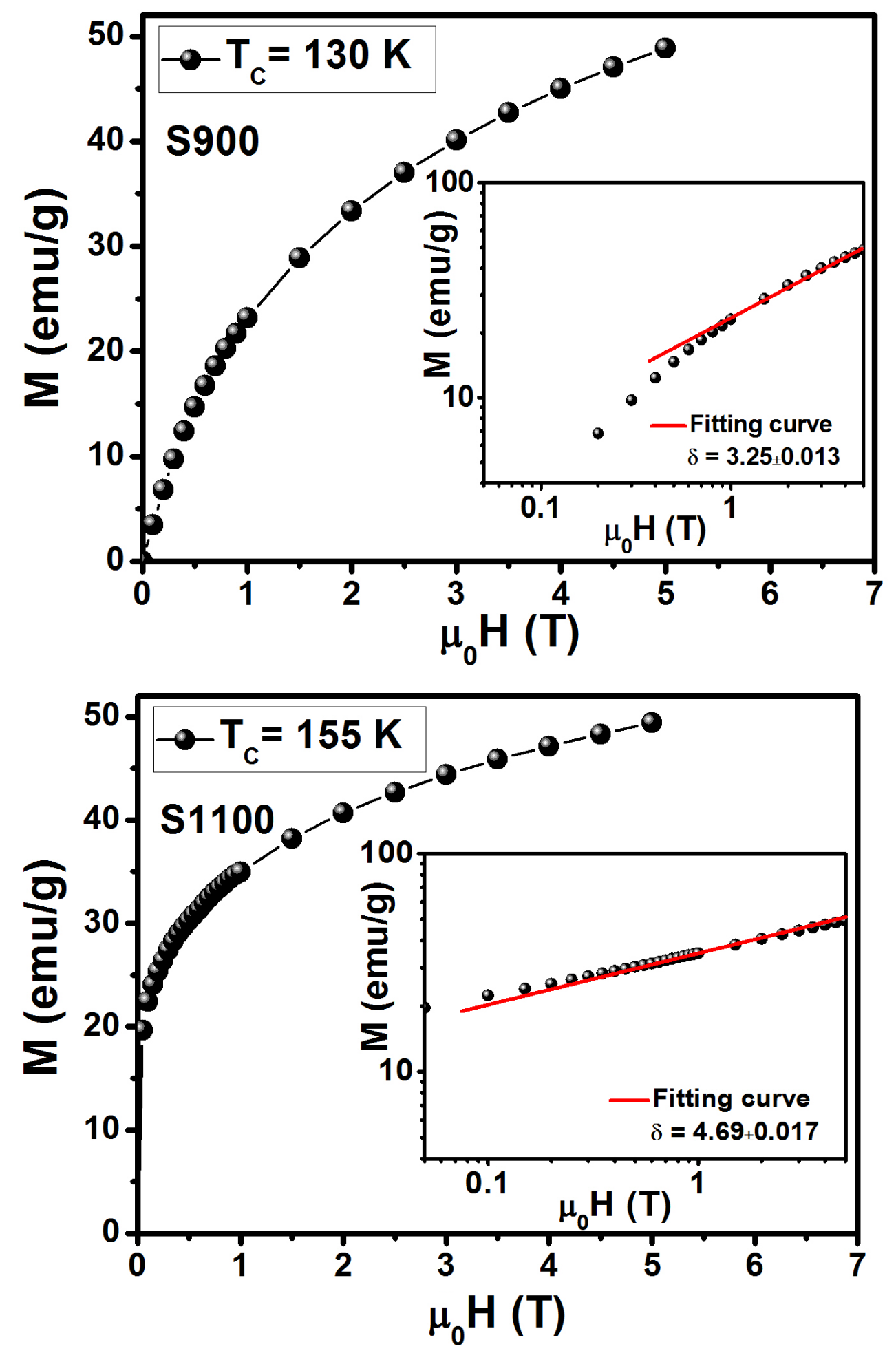

Fig.10: Isothermal $M\left(T_{C}, \mu_{0} H\right)$ plot for $S 900$ and $S 1100$. The inset shows the log-log scale of the curve with the solid line is the linear fit following Eq. (8). 